\title{
Hybrid Speed Controller Design Based on Sliding Mode Controller Performance Study for Vector Controlled Induction Motor Drives
}

\author{
Abdülhamit Nurettin ${ }^{*}$, Nihat İnanç \\ Department of Electrical and Electronic Engineering, Kırıkkale University, Kırıkkale, Turkey \\ Received 19 May 2021; received in revised form 28 June 2021; accepted 29 June 2021 \\ DOI: https://doi.org/10.46604/peti.2021.7717
}

\begin{abstract}
The discontinuous control of the sliding mode control (SMC) law causes chattering phenomenon in system trajectories (the oscillation around the desired value), which results in various unwanted effects such as current harmonics and torque ripples. Therefore, this study aims to investigate the performance of a sliding mode speed controller for a three-phase induction motor (IM) controlled by a rotor flux orientation technique to obtain optimum performance. The study results show that the experimental control gains found in the control law have a clear effect on limiting chattering and the system response speed. According to the study results, a hybrid controller is designed based on the fuzzy logic control (FLC) approach to optimally tune these gains. The designed hybrid controller is verified by experimental approximation of simulations using Matlab/Simulink. The simulation results show that the hybrid controller reduces the chattering phenomenon and improves the system's dynamic performance.
\end{abstract}

Keywords: sliding mode control, hybrid controller, induction motor, Matlab/Simulink

\section{Introduction}

Induction motors (IMs) are used extensively in industrial applications and electric vehicle traction motor applications due to their simple structure, low maintenance, ruggedness, and durability [1-2]. In IMs, torque is obtained from the nonlinear function of fluxes and currents. Asynchronous motors require complex control algorithms due to their nonlinear structure. This difficulty can be overcome with the field-oriented control (FOC) technique, where flux and currents are easily separated from each other. Thus, the speed becomes linearly controllable under certain conditions, such as in separately excited direct current (DC) motors [3]. The two main classifications of FOC schemes are direct field-oriented control (DFOC) and indirect field-oriented control (IFOC), discovered by Blaschke in 1972 [4]. The DFOC method is proposed to measure or estimate the machine flux either by mounted flux sensors in the air gap or by sensing stator voltages; however, this technique is not considered accurate at low speeds [5]. On the other hand, IFOC is synthesized by properly controlling the slip frequency and hence provides higher accuracy over a wide speed range [6]. Therefore, the indirect scheme is preferred over the direct scheme [7]. Conventional proportional-integral (PI) controllers are widely used in FOC techniques [8-9]. However, high dynamic performance cannot be obtained from PI controllers.

In recent studies, various nonlinear control techniques such as sliding mode control (SMC) have been proposed. The SMC concept emerged towards the end of the 1950s and started to spread after Utkin's study in 1977 [10]. The SMC method, also known as variable structure control (VSC), is an effective control method used in the control of systems that are linear

\footnotetext{
* Corresponding author. E-mail address: 99802899@kku.edu.tr
}

Tel.: +905458910564 
and non-linear under changing parameters or external disturbing inputs. High-performance controllers are characterized by high dynamic performance, fast response, and high durability against changes affecting system parameters, where the sliding mode controller is a suitable control technique for IMs.

The switching function in the control law provides a high dynamic response in the transient states and a good performance against uncertainties. However, the switching function causes chattering phenomenon in system trajectories (the oscillation around the desired value), which results in various undesirable effects such as current harmonics and torque ripples. Several advanced studies have been presented to suppress or reduce the chattering phenomenon and torque ripples. Instead of the signum function, the saturation function and choosing the appropriate saturation boundary for the controlled system are used [11-14]. In general, adding a thin boundary layer around the sliding surface can solve the chattering problem. However, the slope of the saturation function is a trade-off between controller performance and chattering reduction. Also, the stability in the layer cannot be guaranteed and insufficient selection of the boundary layer can result in an unstable tracking response.

To overcome these problems, many of the studies on merging the fuzzy inference mechanism, neural networks, and several other algorithms such as lightning search algorithm and metaheuristics algorithm with SMC have been done to design a hybrid controller to realize better performance, high dynamic response, and reduced chattering problem [15-17]. Various studies presented in the literature are based on the hybridization of SMC and fuzzy logic control (FLC). In [18-23], FLC is used to adjust the switching gain value, where the big gain value increases response speed and robustness of the system, but the chattering in the steady-state is high. On the other hand, the small gain value reduces the response speed and robustness of the system, but the chattering in the steady-state is low. However, the gain value obtained directly from FLC output has fixed values and limited change. Also, some studies suggested the use of fuzzy supervisory system to determine the participation rate for each of the two controllers (SMC and FLC) according to the system state. In the transient states, the hybrid controller output is obtained from SMC, while the hybrid controller output is FLC output during the steady states. However, this method greatly increased the complexity of the controller in terms of design and practical application [24-25].

This study presents a sliding mode speed controller design for speed control of a three-phase IM by the FOC technique and the stability of the sliding mode controller verified with Lyapunov stability theory. The second step demonstrates the effect of the experimental control coefficient presented in the control law on the chattering phenomenon reduction and the system response speed. Based on the study results, the third step presents a hybrid controller scheme for speed control of a three-phase IM relying on a supervisory fuzzy logic controller to tune the optimum gain value of the SMC law according to the system condition.

\section{Mathematical Model of IM}

IM can be modelled in a d-q synchronously rotating frame. The motor behaviour is defined by appropriate selection of the stator currents and rotor flux as state variables, using the following equations:

$$
\left[\begin{array}{l}
\frac{d i_{s d}}{d t} \\
\frac{d i_{s q}}{d t} \\
\frac{d \Phi_{r d}}{d t} \\
\frac{d \Phi_{r q}}{d t}
\end{array}\right]=\left[\begin{array}{cccc}
-a_{5} & \omega_{s} & a_{3} & a_{4} \omega \\
-\omega_{s} & -a_{5} & -a_{4} \omega & a_{3} \\
a_{2} & 0 & -a_{1} & \omega_{s}-\omega \\
0 & a_{2} & -\omega_{s}+\omega & -a_{1}
\end{array}\right]\left[\begin{array}{l}
i_{s d} \\
i_{s q} \\
\Phi_{r d} \\
\Phi_{r q}
\end{array}\right]+\left[\begin{array}{ll}
b & 0 \\
0 & b \\
0 & 0 \\
0 & 0
\end{array}\right]\left[\begin{array}{l}
V_{s d} \\
V_{s q}
\end{array}\right]
$$




$$
\begin{aligned}
& a_{1}=\frac{R_{r}}{L_{r}} \\
& a_{2}=\frac{L_{m} R_{r}}{L_{r}} \\
& a_{3}=\frac{L_{m} R_{r}}{\sigma L_{s} L_{r}^{2}} \\
& a_{4}=\frac{L_{m}}{\sigma L_{s} L_{r}} \\
& a_{5}=\frac{L_{r}^{2} R_{S}+L_{m}^{2} R_{r}}{\sigma L_{s} L_{r}^{2}} \\
& b=\frac{1}{\sigma L_{s}} \\
& \sigma=\frac{1-L_{m}^{2}}{L_{S} L_{r}}
\end{aligned}
$$

The motion equation and the electromagnetic torque produced by IM are given by the relations:

$$
\begin{aligned}
& \frac{d \omega}{d t}=\frac{P}{J} T_{e m}-\frac{P}{J} T_{L}-\frac{F}{J} \omega \\
& T_{\mathrm{em}}=\frac{3 P L_{m}}{2 L_{r}}\left(\Phi_{r d} \cdot i_{s q}-\Phi_{r q} \cdot i_{s d}\right)
\end{aligned}
$$

where $P$ is the pole pair number of the motor; $J$ is the total inertia of the system; $F$ is the viscous friction coefficient; $R_{s}$ and $R_{r}$ are the stator and rotor winding resistances; $L_{s}, L_{r}$, and $L_{m}$ are the stator, rotor, and mutual inductances; $\sigma$ is the total leakage factor. The load torque $T_{L}$ is considered an external disturbance. The angular synchronous speed is given by:

$$
\omega_{s}=\omega+\omega_{s l}
$$

where $\omega$ and $\omega_{s l}$ are the rotor and slip angular speed.

\section{Field-Oriented Control (FOC)}

The principle of FOC consists of aligning the $\mathrm{d}$ axis of the revolving reference frame with the rotor flux vector $\phi_{r}$, as illustrated in Fig. 1.

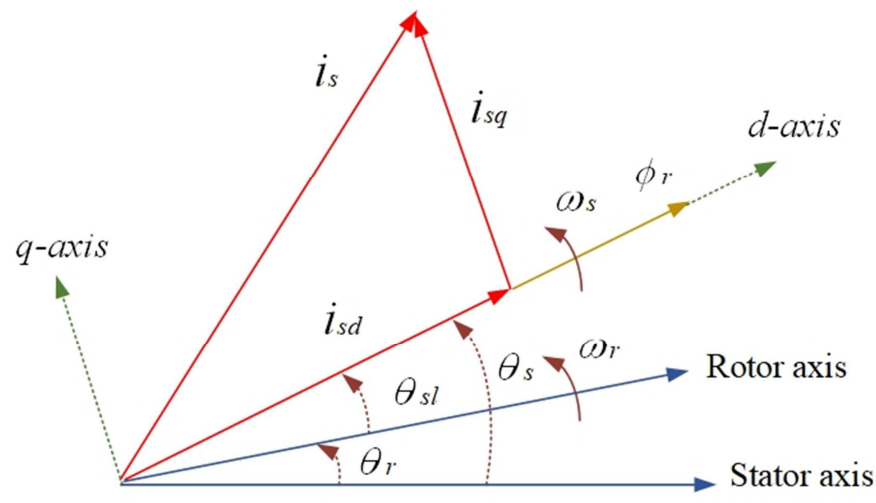

Fig. 1 Phasor diagram explaining IFOC 
Thus, the orientation condition of the rotor flux is $\phi_{r q}=0$ and $\phi_{r d}=\phi_{r}$, and the mathematical model of IM can be expressed using the following equations according to this condition:

$$
\begin{aligned}
& \frac{d i_{s d}}{d t}=-a_{5} i_{s d}+\omega_{s} i_{s q}+a_{3} \phi_{r}+b V_{s d} \\
& \frac{d i_{s q}}{d t}=-\omega_{s} i_{s d}-a_{5} i_{s q}-a_{4} \omega \phi_{r}+b V_{s q} \\
& \frac{d \phi_{r}}{d t}=a_{2} i_{s d}-a_{1} \phi_{r} \\
& 0=a_{2} i_{s q}-\omega_{r} \phi_{r} \\
& T_{e m}=\frac{3}{2} \frac{P L_{m}}{L_{r}} \Phi_{r d} i_{s q}=K_{t} i_{s q}
\end{aligned}
$$

To guarantee a correct alignment of the revolving reference frame, the flux angular position $\theta_{s}$ is obtained to perform the direct and inverse Park transformations as follows:

$$
\theta_{s}=\int \omega_{s} d t=\int\left(\omega+\omega_{s l}\right) d t
$$

The slip angular speed can be calculated by the following equation:

$$
\omega_{s l}=\frac{a_{2} i_{s q}}{\phi_{r d}}=\frac{a_{1} i_{s q}}{i_{s d}}
$$

Fig. 2 shows the block diagram of the FOC algorithm using the studied sliding mode speed controller.

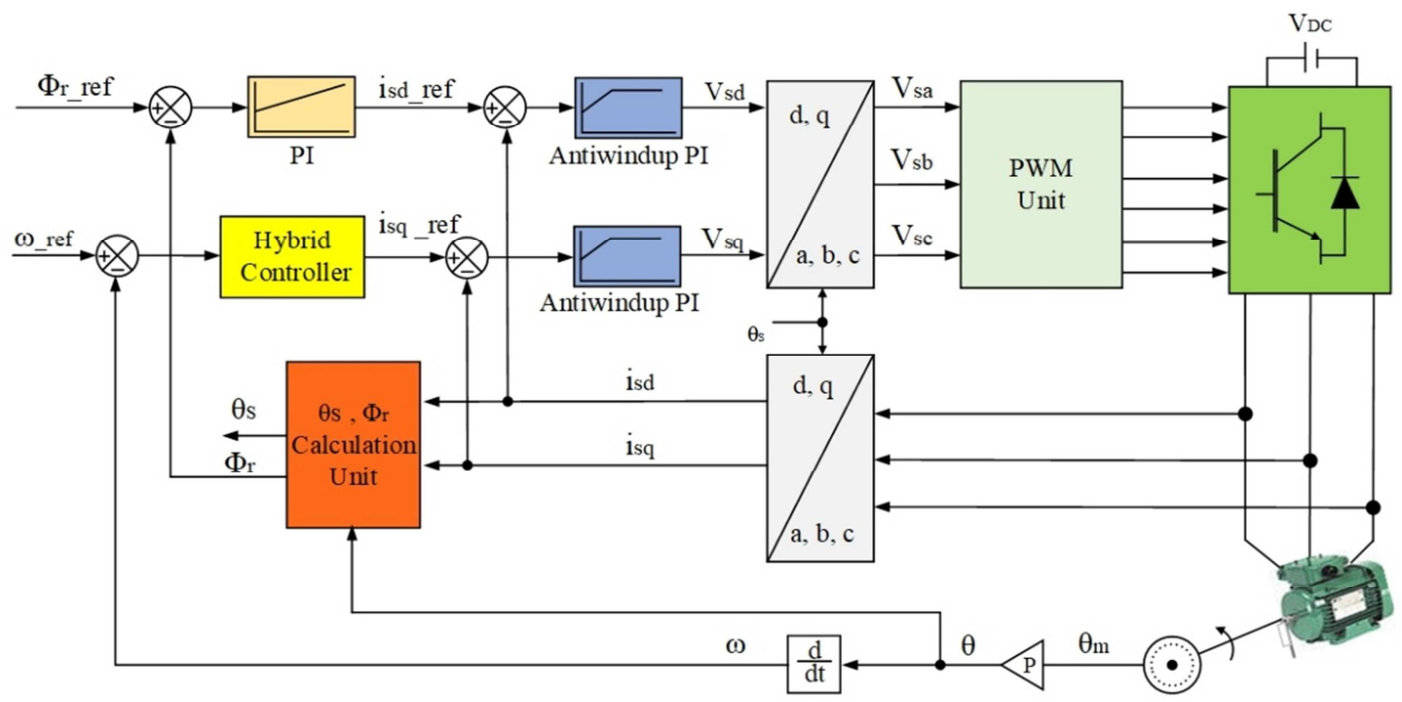

Fig. 2 The FOC algorithm using the studied sliding mode speed controller

\section{Sliding Mode Control (SMC)}

The essential precept of SMC requires a perfect control law to create changes in the system state trajectory on phase planes. The objective is to control the system trajectory to slip along or toward the sliding surface. When the state trajectory arrives at the sliding surface, a switching control law is applied to guarantee that the system trajectory stays on the sliding surface. Ultimately, the trajectory slides to the origin point along the sliding surface, as shown in Fig. 3. 


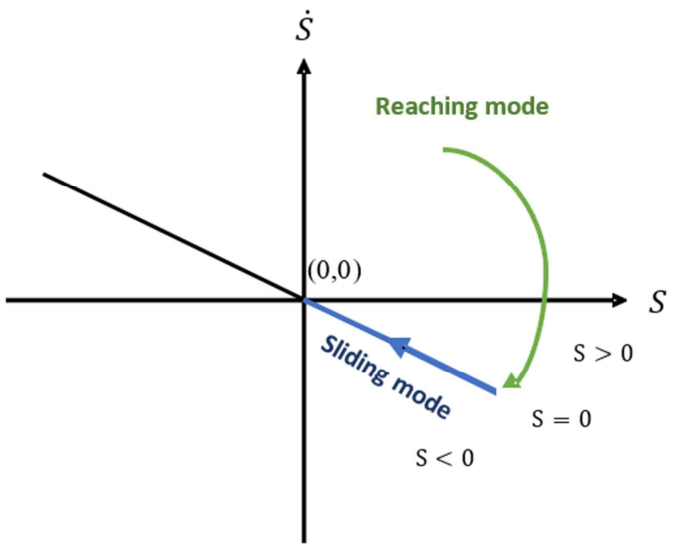

Fig. 3 The reaching and sliding modes for a second-order system

The design of SMC can be achieved in two successive steps:

Step 1: determination of sliding surfaces

The sliding surface is generally defined by:

$$
S(t)=\left(\frac{d}{d t}+\lambda\right)^{n-1}\left(x_{r e f}-x\right)
$$

where $x$ presents the state vector, $x_{\text {ref }}$ indicates the reference state vector, $n$ is the degree of the sliding mode, and $\lambda$ is a constant and $\lambda>0$. A larger $\lambda$ can give a faster response. However, a great value of $\lambda$ could lead to undesired overshoots.

Step 2: control law design

The SMC law has two components and can be expressed as follows:

$$
u(t)=u_{e q}(t)+u_{s w}(t)
$$

The component $u_{e q}$ called equivalent control is obtained by setting the surface derivative to zero $\dot{S}(t)=0$ and purposed to preserve the system state trajectory on the sliding surface which is determined by $S(t)=0$. The other constituent $u_{s w}$ is the switching control (discontinuous control) which guarantees the convergence of the system state trajectory toward the sliding surface. The reaching state is based on Lyapunov stablility theory and is verified by $S . \dot{S}<0$.

\section{Design of Sliding Mode Speed Controller}

From the mechanical equation of an IM, the following equations are obtained:

$$
\begin{aligned}
& T_{e m}-T_{L}=J \frac{d \omega}{d t}+F \omega \Rightarrow \frac{d \omega}{d t}=\frac{1}{J} T_{e m}-\frac{F}{J} \omega-\frac{1}{J} T_{L} \\
& T_{e m}=\frac{3}{2} \frac{P L_{m}}{L_{r}} \Phi_{r d} i_{s q}^{*}=K i_{s q}^{*}
\end{aligned}
$$

where $i_{s q}^{*}$ is the torque current command.

The following is the derivative of Eq. (21):

$$
\ddot{\omega}=\frac{1}{J} \ddot{T}_{e m}-\frac{F}{J} \dot{\omega}
$$


Speed error and its first and second derivative are defined as follows:

$$
\begin{aligned}
& e=\omega^{*}-\omega \\
& \dot{e}=-\dot{\omega} \\
& \ddot{e}=-\ddot{\omega}=-\frac{1}{J} \ddot{T}_{e m}-\frac{F}{J} \dot{e}=-\frac{1}{J} K u_{e q}-\frac{F}{J} \dot{e}
\end{aligned}
$$

where $u_{e q}=d i_{s q}^{*} / d t$ and $\omega^{*}$ is a rotor speed reference.

Eqs. (25) and (26) can be represented using a state equation:

$$
\left[\begin{array}{c}
\dot{e} \\
\ddot{e}
\end{array}\right]=\left[\begin{array}{cc}
0 & 1 \\
0 & -\frac{F}{J}
\end{array}\right]\left[\begin{array}{l}
e \\
\dot{e}
\end{array}\right]+\left[\begin{array}{c}
0 \\
-\frac{K}{J}
\end{array}\right] u_{e q}
$$

The following equation can be obtained by using the sliding surface given in Eq. (19), for $n=2$ :

$$
S=\dot{e}+\lambda e
$$

Equivalent control is obtained by making the sliding surface derivative equal to zero $\dot{S}(t)=0$.

$$
\begin{aligned}
& \dot{S}=\ddot{e}+\lambda \dot{e} \\
& \dot{S}=-\frac{1}{J} K u_{e q}-\frac{F}{J} \dot{e}+\lambda \dot{e}=0
\end{aligned}
$$

Then, the equivalent control $u_{e q}$ can be expressed as follows:

$$
u_{e q}=\frac{1}{K}(J \lambda-F) \dot{e}
$$

Eq. (31) shows the dynamic behaviour of the system on the sliding surface. For the state variable to reach the sliding surface, an appropriate discontinuous control law must be used as shown in the following equation:

$$
u_{s w}=Q \operatorname{sign}(S)+K S ; \text { with } Q, K>0
$$

where $Q$ is switching gain.

$$
\operatorname{sign}(S)=\frac{(S)}{|(S)|}=\left\{\begin{array}{lll}
1 & \text { if } & S>0 \\
0 & \text { if } & S=0 \\
-1 & \text { if } & S<0
\end{array}\right.
$$

The total control equation will be as follows:

$$
u=\frac{1}{K}(J \lambda-F) \dot{e}+Q \operatorname{sign}(S)+K S
$$

Lyapunov stability theory is used to ensure the stability of the sliding mode controller. The Lyapunov function is defined as:

$$
V=\frac{1}{2} S^{2}
$$


The system's stability condition is $\dot{V}<0$. The derivative of Eq. (35) is:

$$
\dot{V}=S \dot{S}
$$

Eq. (37) is obtained from Eqs. (30) and (34) as follows:

$$
\begin{aligned}
& \ddot{S}=-\frac{Q}{J} \operatorname{sign}(S)-\left(\frac{K}{J}\right) S \\
& S \ddot{S}=-S\left(\frac{Q}{J}\right) \operatorname{sign}(S)-\left(\frac{K}{J}\right) S^{2}=-\left(\frac{Q}{J}\right)|S|-\left(\frac{K}{J}\right) S^{2}<0
\end{aligned}
$$

Eq. (38) shows that $Q$ and $K$ must be positive constants to satisfy $\dot{V}<0$ and ensure successful SMC.

\section{The Performance Study of the Designed Sliding Mode Controller}

The sliding mode controller has high dynamic performance, fast response, and high impedance to changes affecting system parameters. However, the main problem is the chattering phenomenon resulting from the discontinuous control law. The experimental control coefficients $Q$ and $K$ presented in the discontinuous control law are of great importance to reduce the chattering phenomenon, but the second term of the discontinuous control law includes the coefficient $K$ multiplied by the sliding function $(\mathrm{S})$ that has a large value in the transient states and a small value in the steady-state which must equal to zero on the sliding surface. Therefore, the switching gain $Q$ has the greatest impact on the performance of the system and reduction on the chattering phenomenon. Thus, the equation expressing the discontinuous control law at variable values of switching gain is given as follows:

$$
u_{s w}=\tilde{Q} \operatorname{sign}(S)+K S
$$

\section{Design of Hybrid Fuzzy Sliding Mode Controller}

The proposed hybrid controller is designed based on the sliding mode controller. The fuzzy logic controller is used as a supervisor controller to adjust the gain value according to the state of the system in both transient and steady states to provide a high dynamic performance of the system. The proposed hybrid controller achieves the advantages of the sliding mode controller and eliminates the disadvantages represented in the experimental gain values and the chattering phenomenon. The advantages can be summarized as follows:

(1) Good stability (small gain value)

(2) Fast transient state (large gain value)

(3) High durability against internal and external disturbances

The fuzzy logic controller tunes the gain value $\tilde{Q}$ shown in Eq. (39). This gain has the largest influence on the system performance in the transient and steady states, and more importantly, on the oscillation of the state variable (speed) controlled on the sliding surface and around the origin point. The adaptive gain value $\tilde{Q}$ is obtaining by Eq. (40) using the participation rate $\eta$ which represents the output of FLC, where a large value $Q_{\max }$ is chosen (providing a high dynamic response to the system without drift problems in the transient states) and a small value $Q_{\min }$ (providing a low chattering in the steady-states). The inputs of the FLC are the sliding surface and the change of the sliding surface $(s, \Delta s)$. 
When the values of the inputs $(s, \Delta s)$ are large (transient state), the value of the participation rate becomes $\eta \approx 1$, so the adaptive gain $\tilde{Q}$ is comprised of a large proportion of the gain $Q_{\max }$ and a small proportion of the gain $Q_{\min }$, but at the small values of the inputs $(s, \Delta s)$, the participation rate will be small and in this case, the adaptive gain $\tilde{Q}$ is made up of a large proportion of $Q_{\min }$ and a small proportion of $Q_{\max }$.

$$
\tilde{Q}=\eta \cdot Q_{\max }+(1-\eta) Q_{\min }
$$

As for the structure of the supervisory FLC, it has been designed with two inputs $(s, \Delta s)$ that have similar membership functions and one output $(\eta)$. The Mamdani method is chosen to calculate the output value. $\mu i(s, \Delta s)$ is the membership functions of inputs $(s, \Delta s)$, which has a triangular and trapezoidal type with fuzzy sets negative $(\mathrm{N})$, zero $(\mathrm{Z})$, and positive $(\mathrm{P})$ as shown in Fig. 4.

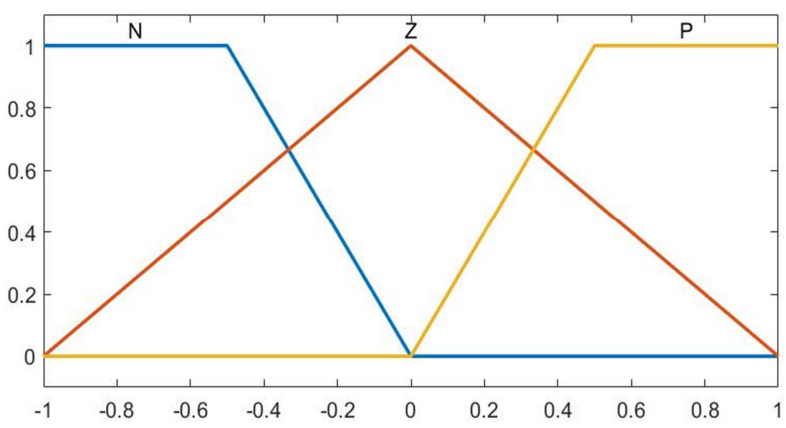

Fig. 4 Fuzzy Input membership function for $s$ and $\Delta s$

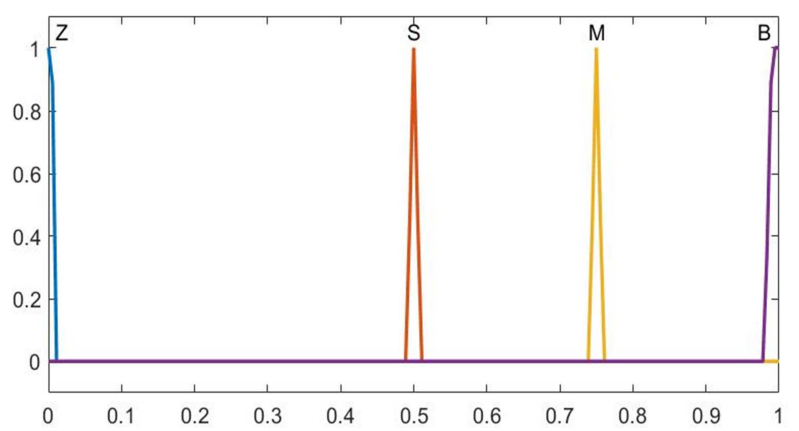

Fig. 5 Fuzzy output membership function for $\eta$

The output membership function by the Mamdani method is defined as triangular and trapezoidal type with fuzzy sets (zero, small, medium, and big) as shown in Fig. 5. The output of the fuzzy system is obtained by using the centroid defuzzer. The nine possible rules $(3 \times 3)$ can be expressed in Table 1 .

Table 1 Fuzzy rules

\begin{tabular}{|c|c|c|c|}
\hline$S S$ & $\mathrm{~N}$ & $\mathrm{Z}$ & $\mathrm{B}$ \\
\hline $\mathrm{N}$ & $\mathrm{B}$ & $\mathrm{S}$ & $\mathrm{M}$ \\
\hline $\mathrm{Z}$ & $\mathrm{B}$ & $\mathrm{Z}$ & $\mathrm{B}$ \\
\hline $\mathrm{B}$ & $\mathrm{M}$ & $\mathrm{S}$ & $\mathrm{B}$ \\
\hline
\end{tabular}

\section{Simulation Results and Discussion}

The validity and effectiveness of the suggested controller are verified by experimental approximating by the simulation using Matlab. Matlab/Simulink is used to model the FOC algorithm, Park and Clarke transformation, PI controllers, the proposed and studied speed control algorithms, and the pulse width modulation (PWM) unit. However, to represent the power part (IM, voltage source converter, DC voltage source, and measurement of the three-phase motor currents), Matlab/SimPowerSystems is used. Fig. 6 shows the system's overall simulation model using Matlab/Simulink and Matlab/SimPowerSystems. The Runge-Kutta method is used to solve differential equations. The sampling time is $T_{S}=20 \mu s$ and the converter switching frequency is set as $5 \mathrm{KHz}$. The nominal parameters of IM are given in Table 2. PI controller gains are tuned using the zero-pole cancellation method. It should be noted that the anti-windup PI controllers are used as d-q axis current controllers to avoid system drift problems at the severe transient states. The purpose of this is to reduce the enormous increase in values of the voltage $\left(V_{s d}, V_{s q}\right)$ vector components due to the high response of current controllers $\left(i_{s d}, i_{s q}\right)$.

Table 2 IM nominal parameters

\begin{tabular}{|c|c|c|c|}
\hline $\mathrm{P}_{\mathrm{n}}=1 \mathrm{KW}$ & $\mathrm{P}=2$ pairs & $\mathrm{U}_{\mathrm{n}}=380 \mathrm{~V}$ & $\mathrm{f}_{\mathrm{n}}=50 \mathrm{~Hz}$ \\
\hline $\mathrm{R}_{\mathrm{s}}=7.2 \boldsymbol{\Omega}$ & $\mathrm{L}_{\mathrm{s}}=0.28 \mathrm{H}$ & $\mathrm{R}_{\mathrm{r}}=1.35 \Omega$ & $\mathrm{L}_{\mathrm{r}}=0.075 \mathrm{H}$ \\
\hline $\mathrm{L}_{\mathrm{m}}=0.118 \mathrm{H}$ & $\mathrm{T}_{\mathrm{L}}=6 \mathrm{~N} . \mathrm{m}$ & $\mathrm{J}=0.006 \mathrm{~kg} . \mathrm{m}^{2}$ & $\mathrm{~F}=0.0046$ N.m.s \\
\hline
\end{tabular}




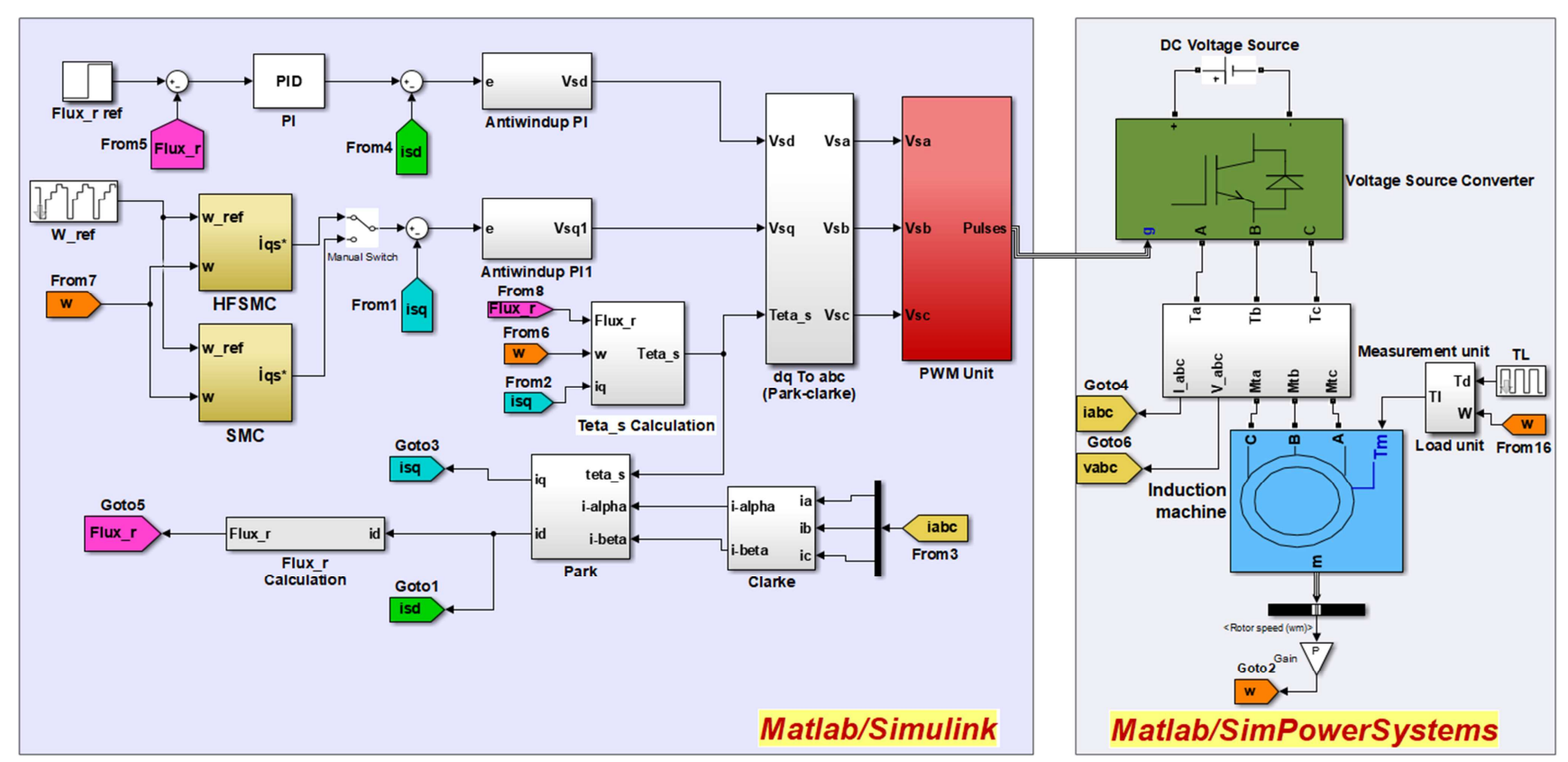

Fig. 6 Overall simulation model

First, the system performance is compared in terms of the chattering phenomenon and response speed when applying variable values of switching gain $Q$ under various operating conditions. Positive and negative variable reference speed and also the nominal load disturbance torque suddenly are applied at $t=0.75 \mathrm{~s}$ and removed at $t=3.5 \mathrm{~s}$. The values of the experimental gains included in the discontinuous control law are chosen as follows: $Q_{1}=5000, Q_{2}=500, Q_{3}=100$, and $K=0.1$.

Fig. 7 shows the speed response at the chosen values of the switching gain $Q$. The large chattering of the rotor speed is observed when a large value is chosen, while the response speed is high during transient states, and conversely, for small values, the chattering phenomenon is significantly reduced, but the response speed is small during transient states. Fig. 8 illustrates the big difference in the occurring chattering in the electromagnetic torque response for the different values of switching gain $Q$. Fig. 9 presents the stator current of phase a, showing the significant distortion of the stator current at the large values of the switching gain $Q$.

To confirm the obtained results for the proposed study, a state variable trajectory is shown in the phase plane for the three values of $Q$. Fig. 10 shows the high reaching speed of the state variable to the sliding surface (high response speed), and also shows the large oscillation around the sliding surface (high chattering) when the large values of switching gain $Q$ are chosen. On the other hand, as the small values are chosen, the state variable takes more time to reach the sliding surface with less oscillation around the sliding surface.

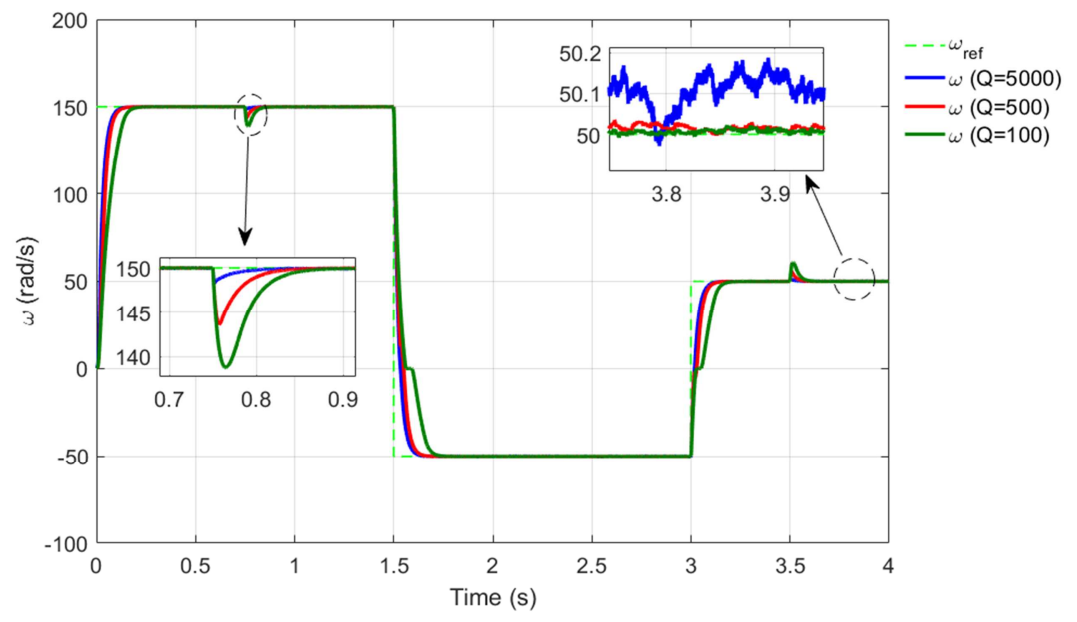

Fig. 7 Speed response 


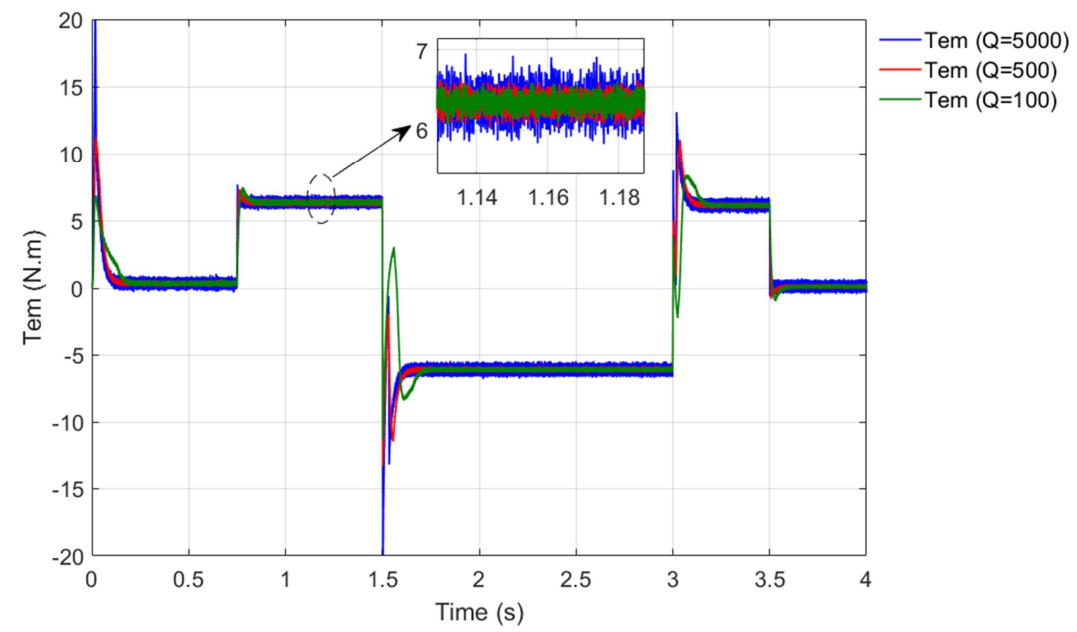

Fig. 8 Electromagnetic torque response

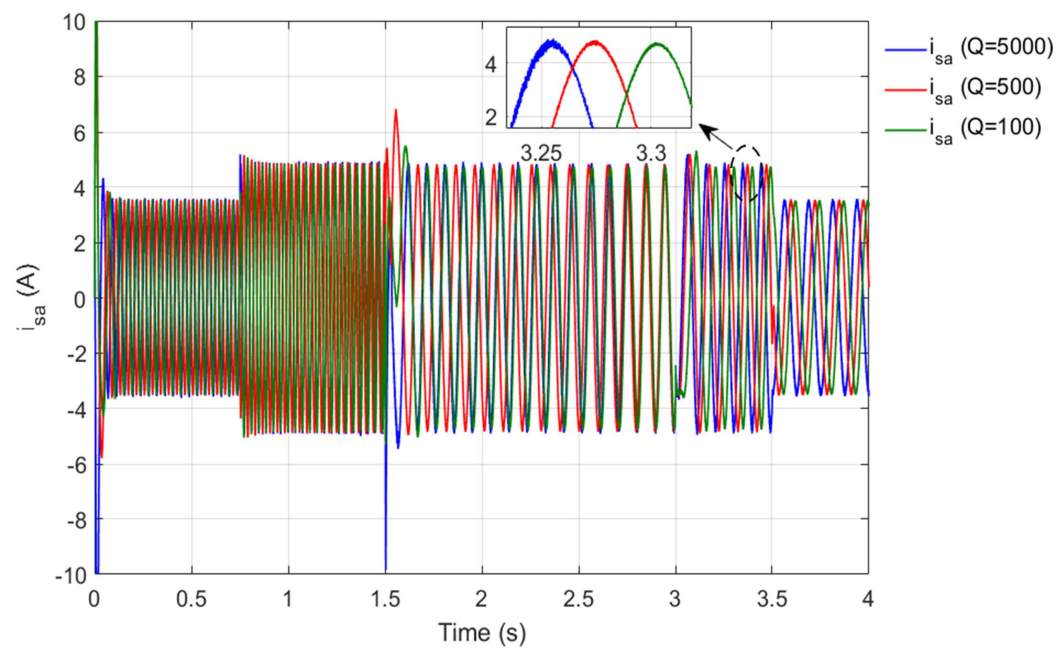

Fig. 9 Stator current of phase a

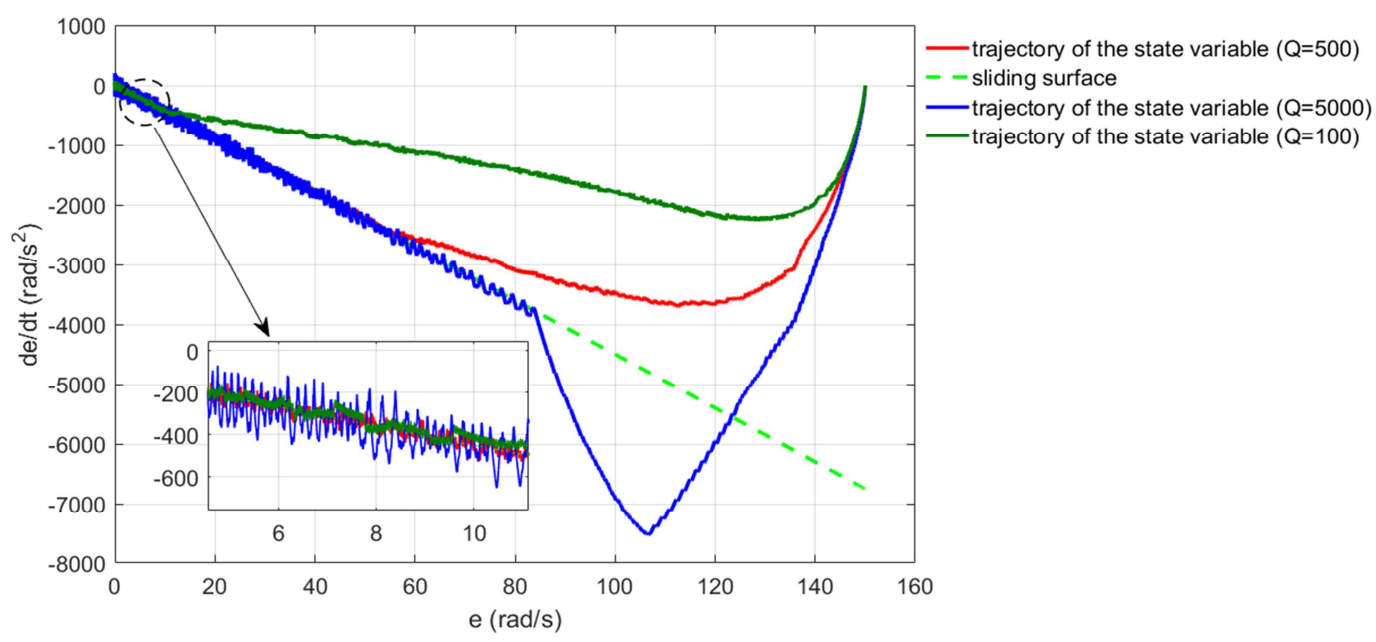

Fig. 10 Phase plane trajectories

Second, under the previous simulation operating conditions, the proposed hybrid controller with SMC is compared. For SMC and hybrid controller, the gains of the control law are chosen as: $K=0.1, Q=2500$ and $K=0.1, Q_{\max }=5000, Q_{\min }=$ 100 respectively. Fig. 11 shows the comparison of the speed response for both the proposed hybrid controller and SMC. It can be seen that the hybrid controller not only maintains the high dynamic performance that is SMC characteristic, but also maintains the ability to reduce the chattering and eliminate the static error in steady-state simultaneously. 
From Fig. 12, it can be noticed the big difference in the occurring chattering in the electromagnetic torque response between the suggested controller and SMC, and this is also given in Fig. 13, where it shows the significant reduction of distortion in the motor currents. Also, a state variable trajectory is shown in the phase plane for the hybrid controller and SMC as given in Fig. 14. It can be observed that there is small oscillation around the sliding surface and origin point (little chattering) for the suggested controller.

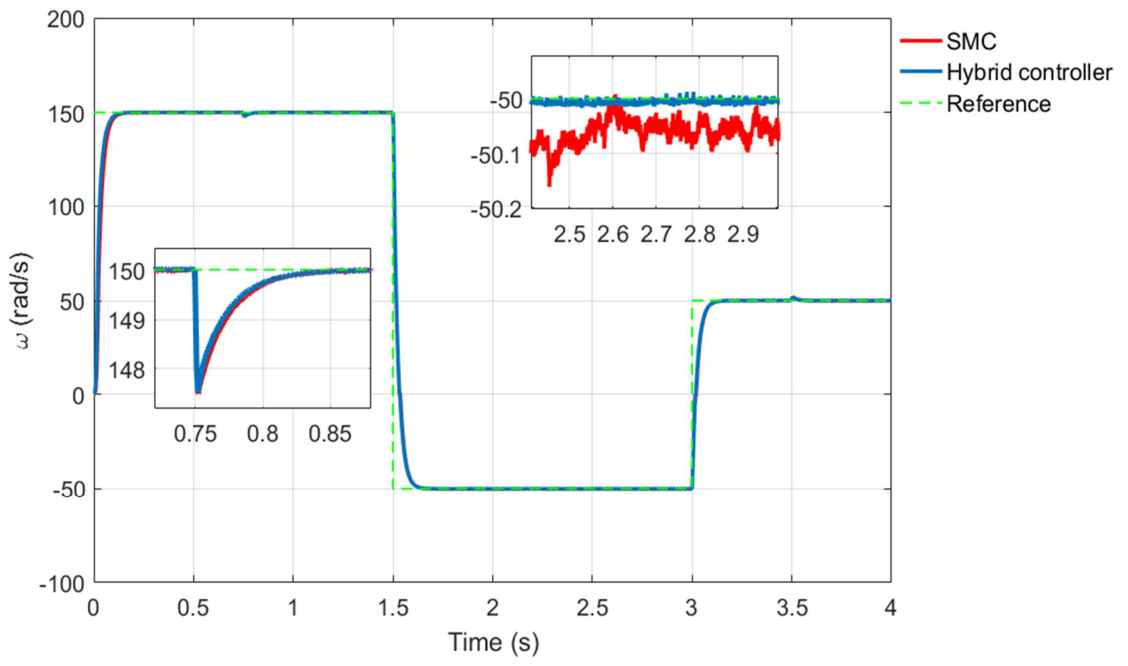

Fig. 11 Speed response

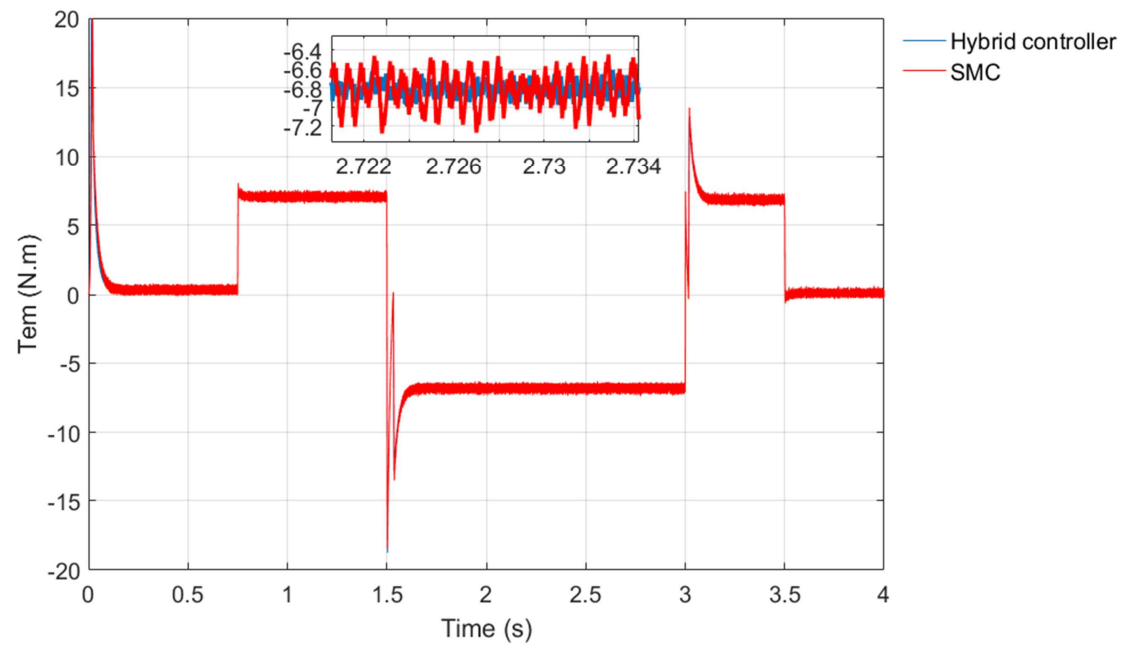

Fig. 12 Electromagnetic torque response

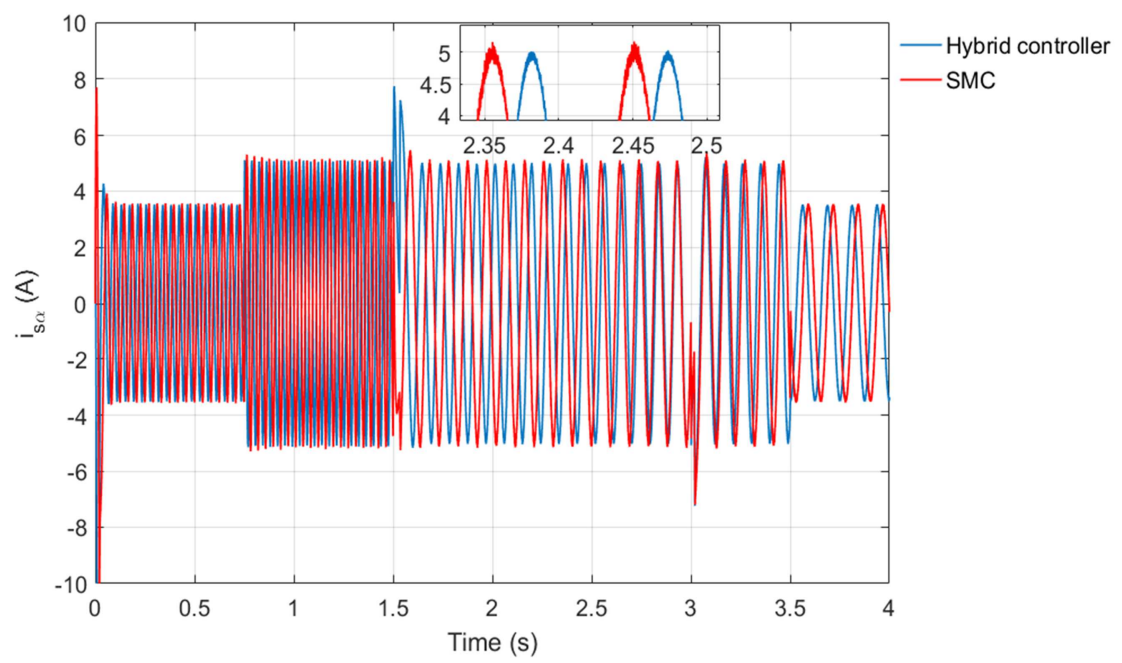

Fig. 13 Stator current of phase a 


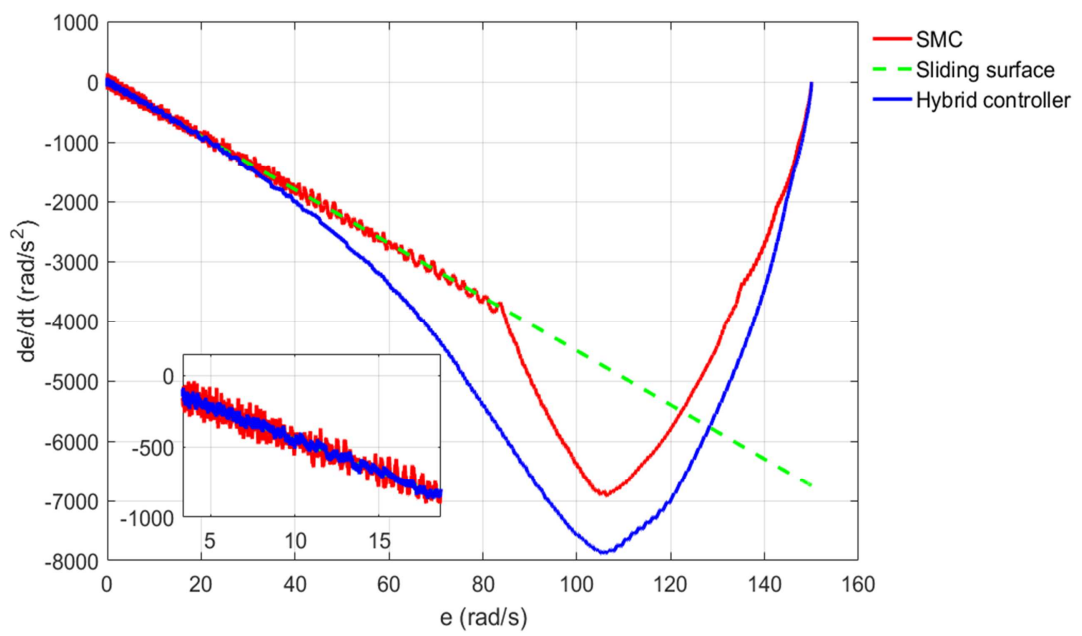

Fig. 14 Phase plane trajectories

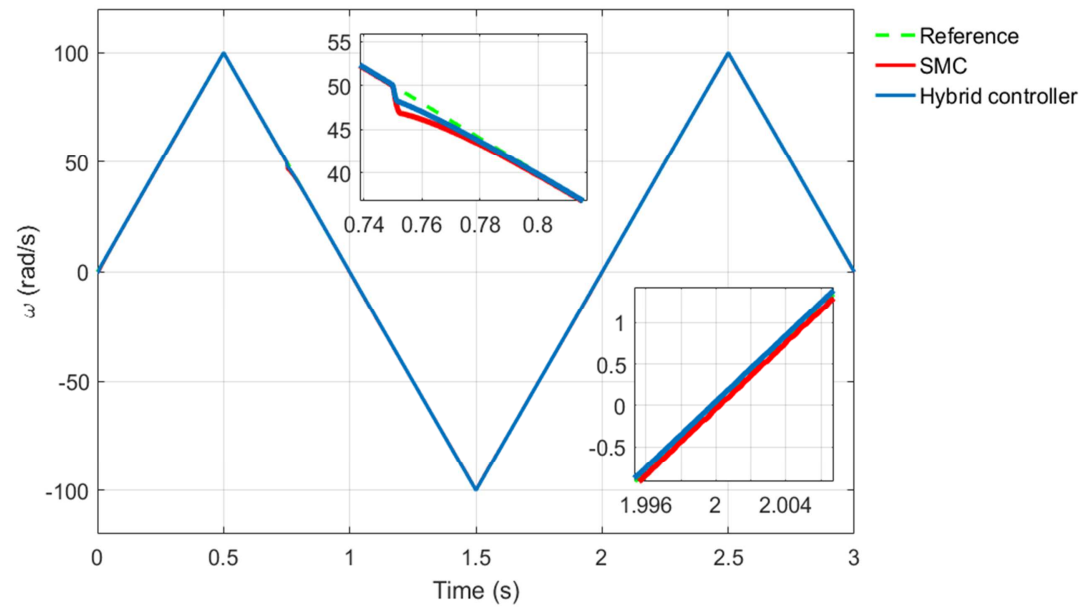

Fig. 15 Speed response for triangular reference speed

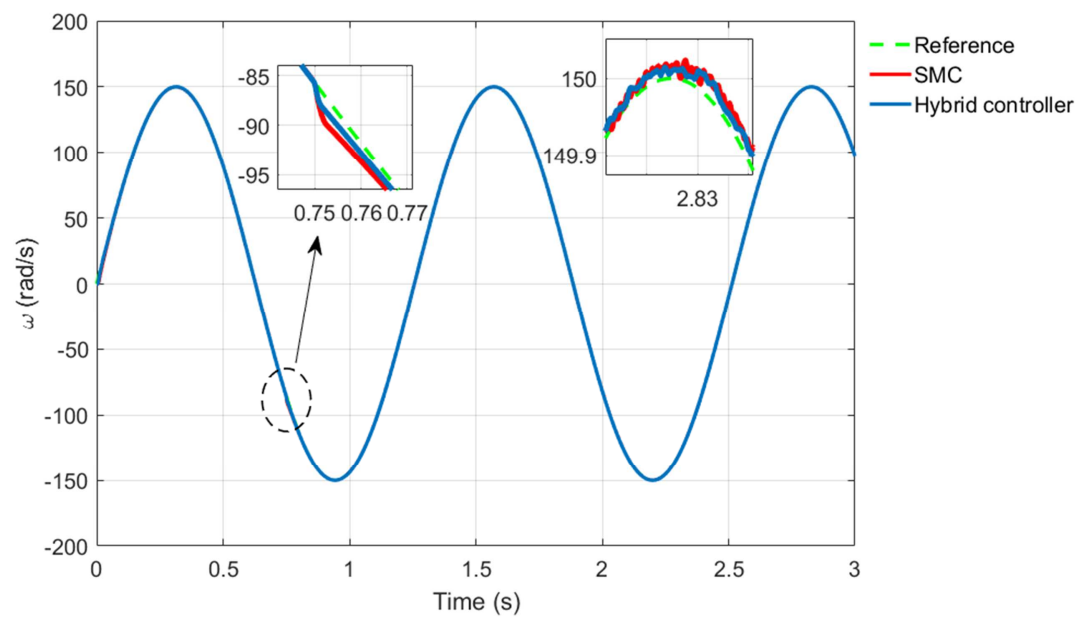

Fig. 16 Speed response for sinusoidal reference speed

The performance of the proposed hybrid controller is also studied and compared with SMC at triangular and sinusoidal reference speeds. Figs. 15 and 16 show the speed response at positive and negative triangular and sinusoidal reference speeds respectively. The high response speed and instant return of speed can be observed tracking the reference speed when the nominal load is applied at $t=0.75 \mathrm{~s}$, and the oscillation reduction in the speed response for the proposed controller can also be observed. From Figs. 17 and 18, the significant difference in the chattering that occurs in the electromagnetic torque response can be seen between the suggested controller and the SMC at positive and negative triangular and sinusoidal reference speeds respectively. 


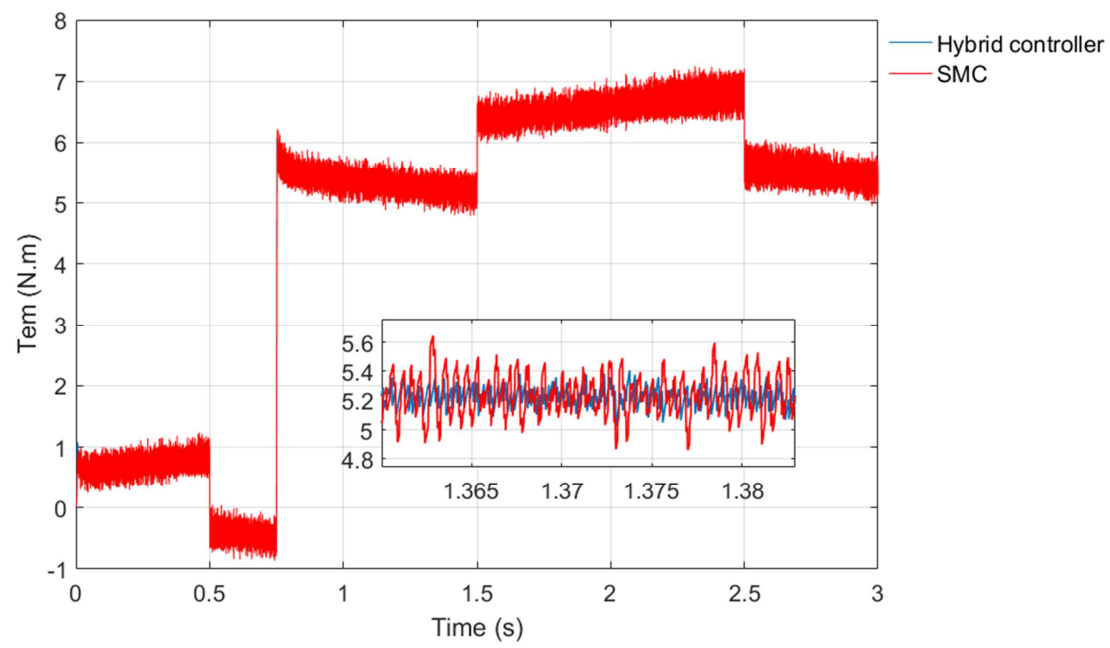

Fig. 17 Electromagnetic torque response for triangular reference speed

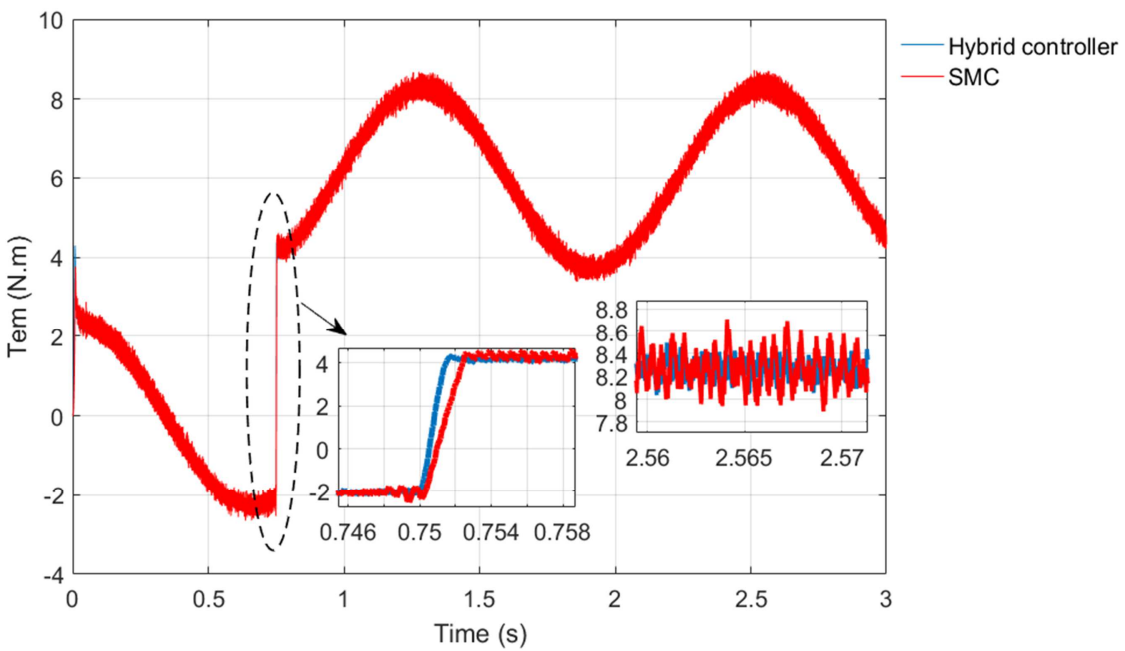

Fig. 18 Electromagnetic torque response for sinusoidal reference speed

\section{Conclusions}

In this study, firstly, a sliding mode speed controller for speed control of a three-phase IM by the rotor flux orientation technique was designed, and the stability of the sliding mode controller based on Lyapunov stability theory was fulfilled. Secondly, the influence of the switching gain of the control law on the performance of the sliding mode speed controller was studied. Thirdly, according to the study results, a hybrid controller based on FLC approach was designed to optimally tune switching gain. Detailed simulation results were presented with an experimental approximation of simulations using Matlab/Simulink. The results proved the superiority and efficiency of the proposed controller, as the results demonstrated that the proposed controller maintained the high dynamic performance, speed of response, and chattering reduction simultaneously. Additionally, to improve the dynamic performance and limit chattering more efficiently, the design of hybrid controllers can be proposed based on second-order sliding mode controllers with the fuzzy logic approach or by using other algorithms such as genetic algorithm and lightning search algorithm to obtain an optimal tuning to the values of the experimental coefficients contained in the control law.

\section{Conflicts of Interest}

The authors declare no conflict of interest. 


\section{References}

[1] A. E. Fitzgerald, C. U. Kingsley, and S. D. Umans, Electric Machinery, 5th ed. New York: McGraw-Hill, 1990.

[2] W. Leonhard, "Controlled AC Drives, a Successful Transition from Ideas to Industrial Practice," Control Engineering Practice, vol. 4, no. 7, pp. 897-908, July 1996.

[3] R. Krishnan, Electric Motors Drives: Modeling, Analysis, and Control, Upper Saddle River: Prentice Hall, 2002.

[4] F. Blaschke, "The Principle of Field Orientation as Applied to the New Transvector Closed-Loop System for RotatingField Machines," Siemens Review, vol. 34, no. 3, pp. 217-220, 1972.

[5] Y. Zhang, Z. Jiang, and X. Yu, "Indirect Field-Oriented Control of Induction Machines Based on Synergetic Control Theory," IEEE Power and Energy Society General Meeting-Conversion and Delivery of Electrical Energy in the 21st Century, July 2008, pp. 1-7.

[6] Z. Guo, J. Zhang, Z. Sun, and C. Zheng, "Indirect Field Oriented Control of Three-Phase Induction Motor Based on Current-Source Inverter,” Procedia Engineering, vol. 174, pp. 588-594, 2017.

[7] B. S. Naik, "Comparison of Direct and Indirect Vector Control of Induction Motor," International Journal of New Technologies in Science and Engineering, vol. 1, no. 1, pp. 110-131, January 2014.

[8] M. J. Vallabhai, P. Swarnkar, and D. M. Deshpande, "PI Control Based Vector Control Strategy for Induction Motor Drive," International Journal of Electronics Communication and Computer Engineering, vol. 3, no. 2, pp. 328-335, March 2012.

[9] R. Gunabalan and V. Subbiah, "Speed Sensorless Vector Control of Induction Motor Drive with PI and Fuzzy Controller," International Journal of Power Electronics and Drive System, vol. 5, no. 3, pp. 315-325, 2015.

[10] V. Utkin, "Variable Structure Systems with Sliding Modes," IEEE Transaction on Automatic Control, vol. 22, no. 2, pp. 212- 222, April 1977.

[11] B. N. Kar, S. Choudhury, K. B. Mohanty, and M. Singh, "Indirect Vector Control of Induction Motor Using SlidingMode Controller," International Conference on Sustainable Energy and Intelligent Systems, July 2011, pp. 507-511.

[12] F. A. Patakor, M. Sulaiman, and Z. Ibrahim, "Sliding Mode Speed Control for Induction Motor Drives with StateDependent Gain Method," International Review of Electrical Engineering, vol. 8, no. 5, pp. 1446-1453, 2013.

[13] K. Zeb, A. Haider, W. Uddin, M. B. Qureshi, C. A. Mehmood, A. Jazlan, et al., "Indirect Vector Control of Induction Motor Using Adaptive Sliding Mode Controller," Australian Control Conference, November 2016, pp. 358-363.

[14] C. M. Oliveira, M. L. Aguiar, J. R. Monteiro, W. C. Pereira, G. T. Paula, and T. E. Almeida, "Vector Control of Induction Motor Using an Integral Sliding Mode Controller with Anti-Windup," Journal of Control, Automation, and Electrical Systems, vol. 27, no. 2, pp.169-178, April 2016.

[15] Y. C. Liu, S. Laghrouche, A. N'Diaye, and M. Cirrincione, "Hermite Neural Network-Based Second-Order SlidingMode Control of Synchronous Reluctance Motor Drive Systems," Journal of the Franklin Institute, vol. 358, no. 1, pp. 400-427, January 2021.

[16] M. Elsisi and H. Abdelfattah, "New Design of Variable Structure Control Based on Lightning Search Algorithm for Nuclear Reactor Power System Considering Load-Following Operation,” Nuclear Engineering and Technology, vol. 52, no. 3, pp. 544-551, March 2020.

[17] M. Elsisi, "New Variable Structure Control Based on Different Meta-Heuristics Algorithms for Frequency Regulation Considering Nonlinearities Effects," International Transactions on Electrical Energy Systems, vol. 30, no. 7, e12428, July 2020.

[18] Y. Yang, Y. Chen, Y. Chu, Y. Wang, and Q. Liang, "Fractional Order Adaptive Sliding Mode Controller for Permanent Magnet Synchronous Motor," Chinese Control Conference, July 2016, pp. 3412-3416.

[19] E. Zaidi, K. Marouani, H. Bouadi, A. E. Kassel, L. Bentouhami, and E. Merabet, "Fuzzy Sliding Mode Method for Speed Regulation of a Dual Star Induction Machine Drive Fed by Multi-Level Inverters," International Conference on Applied Smart Systems, November 2018, pp. 3412-3416.

[20] N. Ettalabi, M. Bouzi, B. Bossoufi, K. Anoune, and E. Mouncef, "Fuzzy-Sliding Mode Speed Control of Permanent Magnet Synchronous Motor Using NPC Converter," International Journal of Engineering Research and Technology, vol. 13, no. 7, pp. 1649-1657, 2020.

[21] K. M. A. Prasad and U. Nair, "Intelligent Fuzzy Sliding Mode Controller Based on FPGA for the Speed Control of a BLDC Motor," International Journal of Power Electronics and Drive System, vol. 11, no. 1, pp. 477-486, March 2020.

[22] S. Y. Chen, H. H. Chiang, T. S. Liu, and C. H. Chang, "Precision Motion Control of Permanent Magnet Linear Synchronous Motors Using Adaptive Fuzzy Fractional-Order Sliding-Mode Control," IEEE/ASME Transactions on Mechatronics, vol. 24, no. 2, pp. 741-752, April 2019. 
[23] L. Yipeng, L. Jie, Z. Fengge, and Z. Ming, "Fuzzy Sliding Mode Control of Magnetic Levitation System of Controllable Excitation Linear Synchronous Motor,” IEEE Transactions on Industry Applications, vol. 56, no. 5, pp. 5585-5592, September-October 2020.

[24] H. Ahmed and A. Rajoriya, "A Hybrid of Sliding Mode Control and Fuzzy Logic Control Using a Fuzzy Supervisory Switched System for DC Motor Speed Control,” Turkish Journal of Electrical Engineering and Computer Sciences, vol. 25, no. 3, pp. 1993-2004, 2017.

[25] N. Layadi, A. Djerioui, S. Zeghlache, A. Houari, M. F. Benkhoris, and F. Berrabah, "A Hybrid Fuzzy Sliding Mode Controller for a Double Star Induction Machine," International Conference on Communications and Electrical Engineering, December 2018, pp. 1-6.

Copyright@ by the authors. Licensee TAETI, Taiwan. This article is an open access article distributed under the terms and conditions of the Creative Commons Attribution (CC BY-NC) license (https://creativecommons.org/licenses/by-nc/4.0/). 